\title{
CLINICAL AND INVESTIGATION PROFILE OF SUBACUTE SCLEROSING PANENCEPHATITIS (SSPE): AN ANALYSIS OF TWENTY CASES
}

\author{
SAHA NC ${ }^{1}$, SULTANA N ${ }^{2}$, MOLLAH MAH ${ }^{3}$, YASMIN L L ${ }^{4}$ ANWAR $\mathrm{S}^{1}$
}

\begin{abstract}
Objective: To identify common clinical features, sociodemographic characteristics and laboratory parameters of diagnosed cases of Subacute Sclerosing Panencephalitis.

Design: Cross sectional descriptive type of study.

Setting: Department of Paediatrics, Dhaka Medical College Hospital.

Study period: January 2006 to December 2008.

Subjects: Twenty clinically diagnosed patients of SSPE.

Results: The mean age at presentation was 8 years. Male: Female ratio was 19:1. Most of the patients came from lower socio-economic group (70\%). Forty five percent had history of primary measles infection and seventy percent were vaccinated against measles. Most common presenting features were fall to ground (95\%), cognitive decline (85\%), myoclonic seizures (80\%), altered speech (70\%), gait disturbance (60\%), personality changes (55\%), dysphagia (50\%) and less commonly blindness (20\%). EEG showed abnormal findings in 100\% of patients who underwent this test. Measles specific IgG antibody in CSF was positive in 90\% cases. Neuroimaging findings were abnormal in $43 \%$ cases.

Conclusion: The diagnosis of SSPE should be considered in children presenting with deteriorating milestones of development especially cognition and behavior, fall to ground along with myoclonic jerks in an endemic country for measles infection. Investigations like CSF and serum antibody to measles virus and characteristic EEG changes may help further in the diagnosis.
\end{abstract}

Key words: SSPE, Myoclonic jerks, Milestones regression, Measles antibody, EEG.

J Dhaka Med Coll. 2008; 17(2) : 72-77.

\section{Introduction:}

Subacute Sclerosing Panencephalitis (SSPE) is a subacute inflammation of brain with a predominant childhood onset, caused by persistence of mutant measles virus in the central system (CNS) ${ }^{1,2}$. The persistence of infection leads to degenerative changes in the brain resulting in progressive regression of acquired milestone of development, intelligence, alterations in behavior and myoclonic seizures and finally to death ${ }^{3-6}$.

It is estimated that the incidence of SSPE worldwide is 1 per million ${ }^{2,3}$. SSPE is rare in developed countries and a decline in frequency has been noticed because of widespread immunization against measles, whereas it continues to be high in developing countries like India, 21 per million and in Pakistan, 10 per million because of indifferent vaccination compliance ${ }^{1-3,7-11}$. SSPE incidence closely relates to measles incidence ${ }^{2}$. There is no data about SSPE incidence in Bangladesh which can be indirectly assumed from the high prevalence of measles in spite of wide vaccination coverage. In Bangladesh with a population of around 146 million, though the routine measles vaccination coverage is $71 \%$, with a

1. Associate Professor, Department of Paediatrics, Dhaka Medical College \& Hospital, Dhaka

2. Medical Officer, Department of Paediatrics, Dhaka Medical College Hospital, Dhaka

3. Professor, Department of Paediatrics, Dhaka Medical College \& Hospital, Dhaka

4. Resident Physician, Department of Paediatrics, Dhaka Medical College Hospital, Dhaka

Correspondence : Dr. Narayan Chandra Saha 
vaccine efficacy of $85 \%$, yet it is estimated that $40 \%$ of children in each birth cohort remain susceptible to measles. This susceptibility is due to dropout, left out, and failure to develop immunity. Furthermore an estimated 20,000 children under five years of age die of measles annually, making it the fifth leading cause of death in this age group ${ }^{12}$, ${ }^{13}$.SSPE risk is at least 10 times lower (5-50 times) in individuals after vaccination compared to the risk in individuals who had measles ${ }^{14}$. Though many treatment protocols have been tried but no effective treatment is available till now.

This study was carried out to observe the clinical presentation and to find out the investigation profile of SSPE cases.

\section{Material and Methods:}

This study was carried out in the Department of Paediatrics, Dhaka Medical College Hospital during the period of January 2006-December 2008. During the period all cases compatible with the clinical diagnosis of SSPE were included.

The diagnosis was based on history that included age at presentation, history of measles, measles vaccination coverage, regression of milestone of development and presenting symptoms like personality change, cognitive decline, myoclonic seizure, falls to ground, loss of spontaneous speech, blindness and dysphagia. Thorough physical and systemic examinations were done. The nervous system examination includes mental state, motor and sensory deficits, ophthalmologic examination. Specific investigations include CSF routine examination as well as serum and CSF measles antibodies. However, the diagnosis was based on a combination of clinical features that was supported by investigations like measles specific antibody titers in CSF and serum, compatible EEG and neuroimaging findings. When clinical and laboratory parameters supported the diagnosis of SSPE then the case was included in the study and the findings were recorded on a previously prepared standard data collection form. Though brain biopsy is essential to confirm the diagnosis but it was not feasible practically. Their family income was also assessed as per criteria of Bangladesh Bureau of Statistics.

\section{Results:}

A total of 20 cases of SSPE were included in this study. The age of presentation of SSPE ranged from 4 years to 12 years with a mean age of onset at 8 years. The maximum number $(70 \%)$ of patients was in 5-10 years age group (Table-1). Among all the patients, 19 (95\%) were male and $1(5 \%)$ was female with the male female ratio of 19:1(Table-II). Most of the patients $(70 \%)$ came from lower socio-economic group (Table-III). Among 20 patients, 9 (45\%) patients had history of measles infection, 7 (35\%) had no history and $4(20 \%)$ could not remember occurrence of measles and 14 (70\%) patients were vaccinated against measles (Table-IV).

\section{Table-I}

Distribution of study population according to age at presentation $(n=20)$

\begin{tabular}{lcc}
\hline Age in years & $\begin{array}{c}\text { Number } \\
\text { of Patient }\end{array}$ & $\begin{array}{c}\text { Percentage } \\
(\%)\end{array}$ \\
\hline Below 5 years & 4 & $20 \%$ \\
5-10 years & 14 & $70 \%$ \\
Above 10 years & 2 & $10 \%$ \\
\hline Total & 20 & $100 \%$ \\
\hline
\end{tabular}

Table-II

Sex distribution of study population $(n=20)$

\begin{tabular}{lcc}
\hline Sex & $\begin{array}{c}\text { Number } \\
\text { of Patient }\end{array}$ & $\begin{array}{c}\text { Percentage } \\
(\%)\end{array}$ \\
\hline Male & 19 & $95 \%$ \\
Female & 1 & $5 \%$ \\
\hline Total & 20 & $100 \%$ \\
\hline
\end{tabular}

Table-III

Economic status of the cases $(N=20)$.

\begin{tabular}{lcc}
\hline Family income/month & Numbers & Percentage (\%) \\
\hline Less than Tk. 4000 & 14 & $70 \%$ \\
More than Tk. 4000 & 6 & $30 \%$ \\
\hline Total & 20 & $100 \%$ \\
\hline
\end{tabular}

$14(70 \%)$ patients came from poor family income group (< Tk 4000 / month) and another $6(30 \%)$ patients belonged to middle class (Tk. 4000 or more / month) family (Table-III). 
Table-IV

Past history of measles and measles vaccination $(n=20)$

\begin{tabular}{lcc}
\hline Past history & Number & Percentage \\
\hline Measles & 9 & 45 \\
Measles vaccination & 14 & 70 \\
\hline
\end{tabular}

Table-V

Clinical presentation at admission of studied children $(N=20)$

\begin{tabular}{lcc}
\hline Clinical Presentation & Number & Percentage \\
\hline Psychosocial Change & & \\
Personality Change & 11 & $55 \%$ \\
Cognitive decline & 17 & $85 \%$ \\
Decreased school & 11 & $55 \%$ \\
performance & & \\
Motor function alterations & & \\
Gait disturbance & 12 & $60 \%$ \\
Myoclonic seizure & 16 & $80 \%$ \\
Falls to ground & 19 & $95 \%$ \\
Speech impairment & & \\
Loss of spontaneous & 14 & $70 \%$ \\
speech & & \\
Neurological sign-symptoms & \\
Spasticity & 12 & $60 \%$ \\
Clonus & 8 & $40 \%$ \\
Convulsion & 7 & $35 \%$ \\
Ophthalmic involvement & & \\
Blindness & 4 & $20 \%$ \\
Clinical stage & & $5 \%$ \\
Stage I & 1 & $50 \%$ \\
Stage II & 18 & $90 \%$ \\
Stage III & 1 & 5 \\
Dysphagia & 10 & $50 \%$ \\
\hline
\end{tabular}

The presenting symptoms were personality change $(55 \%)$, cognitive decline $(85 \%)$ and decreased school performance (55\%) cases and the neurological sign-symptoms were gait disturbance $(60 \%)$, myoclonic seizure $(80 \%)$ and fall to ground $(95 \%)$. Other involvements were speech impairment (70\%), spasticity (60\%), clonus $(40 \%)$, dysphagia (50\%) and blindness $(50 \%)$.Ninety percent of the patient presented in clinical stage II (Table-V).
Table-VI

CSF, Serological and EEG findings of the study population

\begin{tabular}{lcc}
\hline Investigation & No & $\%$ \\
\hline Measles antibody in CSF $(\mathrm{n}=20)$ & & \\
IgG positive & 18 & 90 \\
IgG negative & 02 & 10 \\
Measles antibody in serum $(\mathrm{n}=12)$ & & \\
IgG positive & 12 & 100 \\
EEG (n=15) Periodic discharge & 12 & 80 \\
Generalized spike & 02 & 13.3 \\
Slow wave & 01 & 6.7 \\
\hline
\end{tabular}

CSF study for measles antibody was done in all patients. Among them 18 patients were measles specific IgG positive (90\%) and 2 were negative, but they had positive serum measles antibody (60\%).

EEG was done in 15 patients and $100 \%$ of them had an abnormal finding which includes periodic complexes (80\%), generalized spike $(13.3 \%)$ and slow wave in $6.7 \%$ cases (Table$\mathrm{VI})$.

Table-VII

Neuroimaging findings of the patients $(N-7)$

\begin{tabular}{lcc}
\hline Imaging findings & No & $\%$ \\
\hline Normal & 4 & $57 \%$ \\
Abnormal & 3 & $43 \%$ \\
$\quad$ Cortical atrophy & 1 & $14.33 \%$ \\
$\quad$ White matter hyper & 1 & $14.33 \%$ \\
$\quad$ intense signals & & \\
$\quad$ Ischemic change / Infarct & 1 & $14.33 \%$ \\
\hline
\end{tabular}

Out of 20 patients MRI/CT scan of brain were done in 7 patients. Four (57\%) patients had normal imaging and 3 (43\%) had abnormal findings. One each had cortical atrophy (14.33\%), white matter hyper intense signals and ischemic change / infarct (Table-VII).

\section{Discussion:}

Subacute Sclerosing Panencephatitis (SSPE) is a rare progressive neurological disorder that results as an indirect sequel to measles infection $^{3}$. SSPE incidence closely relates to measles incidence. Recognizing the high 
occurrence of measles, this study documented the common clinical and investigation profiles of SSPE cases from a tertiary care hospital of Dhaka city. Regarding age incidence, SSPE is a disease of childhood and early adolescence ${ }^{3}$. The average age of presentation worldwide is between 5 and 15 years with the mean age being $9-10$ years ${ }^{15}$. In the present study, $70 \%$ of the children were within age group of 5-10 years with a mean age of 8 years, which is consistent with above mentioned study and with the reports of Akram et al ${ }^{16}$.

SSPE is approximately twice as common in boys as in girls ${ }^{3,16}$. The incidence is higher in males with a ratio of 2-4:1 female, although primary measles infection shows no such sex disparity 6,7 . In this study $95 \%$ population were male which correlates with the report of Garg and Cruzeiro ${ }^{3,6,7}$ and also reflects gender disparity in seeking medical advice. In the present study $70 \%(n=14)$ patients came from low income group, which is in conformity with other studies that SSPE occurs mostly in lower socio-economic group 14,17 .

SSPE is a post-measles complication ${ }^{18}$, in this study $35 \%(n=7)$ of patients did not have any symptomatic primary measles infection. It may be due to subclinical measles infection ${ }^{9}$ or of ignorance of parents about identification of measles infection. As regards to vaccination, SSPE may develop in vaccinated children. Several reports suggested that this occurrence may be due to high prevalence of malnutrition in developing countries, improper vaccine coverage, poor quality, improper storage and transport of vaccine, subclinical measles infection prior to vaccination, poor seroconversion or vaccine failure, or circulation of atypical / wild measles virus strain ${ }^{9-11,17 .}$

In the study though $70 \%(n=14)$ of the patient were vaccinated, yet developed SSPE, which is not unlikely to happen in the presence of one or more factors mentioned above related to measles vaccination. The occurrence of SSPE among vaccinated children has also been reported by $\mathrm{Akram}^{16}$ in $86 \%$ cases from Pakistan which is similar to the present report. There are no reported cases of vaccine associated SSPE because the DNA sequence of measles vaccine is different from those that of measles virus which causes SSPE 19,20.Moreover ,epidemiological and virological data from meta-analysis suggests that measles vaccine does not cause $\mathrm{SSPE}^{11}$.

The milestones of development were normal in all cases before illness which deteriorated during clinical course of the disease. In this study, cognitive decline was present in $85 \%$ patients and $95 \%$ of study population presented with $\mathrm{H} / \mathrm{O}$ fall on ground. The study by Akram et al ${ }^{16}$ documented the cognitive decline in $86 \%$ patients and motor regression in $100 \%$, which is consistent with the present study. In the clinical stage II, myoclonic seizure is the predominant feature of SSPE. Myoclonic seizures were present in $80 \%$ of study population which was present in $74 \%$ of cases by Akram et al ${ }^{16}$. Seven (35\%) patients developed other types of seizure during the course of the disease. Besides myoclonic jerks, occurrence of other types of seizures has also been reported by Garg3,7. 20\% of children presented with blindness which is one of the presentations in advanced stage of disease. Visual loss of variable type and severity has also been reported by different observers ${ }^{3,15,17}$. The clinical characteristics of this study also coincide with those reported from Dhaka by Alam et al ${ }^{17}$ and other studies described in the literature $7,15,21$.

The most sensitive ELISA method was adopted for detecting measles antibodies in CSF and serum ${ }^{22}$. In the CSF, measles specific IgG antibody was positive in $90 \%$ of studied population whereas the corresponding antibody in serum was positive in $100 \%$ cases $(n=12)$. Diagnosis of SSPE was confirmed by elevated titers of measles antibodies in cerebrospinal fluid in other studies also $7,9,15,16$. In SSPE, measles specific antibodies are found in the CSF due to intrathecal production of antibodies as specific immune response to virus in the central nervous system ${ }^{23}$. The anti measles antibody in CSF was positive in $100 \%$ of patients with SSPE in another study by Akram et $\mathrm{al}^{16}$.

EEG was done in 15 cases, all of them showed abnormal EEG changes. The periodic complexes 
Comparison of clinical and investigation profile of SSPE between two studies from Dhaka.

\begin{tabular}{lcc}
\hline Feature & $\begin{array}{c}\text { Present study 2009,n=20 } \\
\mathrm{n}(\%)\end{array}$ & $\begin{array}{c}\text { Alam et al 2007,n=20 } \\
\mathrm{n}(\%)\end{array}$ \\
\hline Mean age (years) & 7.6 & 6.9 \\
Sex (male: female) & $19: 1$ & $4: 1$ \\
Cognitive decline & $17(85 \%)$ & $17(85 \%)$ \\
Myoclonus & $16(80 \%)$ & $20(100 \%)$ \\
Fall to ground & $19(95 \%)$ & $18(90 \%)$ \\
Altered speech & $14(70 \%)$ & $18(90 \%)$ \\
Vision loss & $4(20 \%)$ & $3(15 \%)$ \\
Measles antibody: & & \\
$\quad$ Positive CSF IgG & $18(90 \%)$ & $20(100 \%)$ \\
Positive serum IgG & $12(100 \%)^{*}$ & $15(75 \%)$ \\
EEG: & & $19(95 \%)$ \\
Periodic complex & $12(80 \%)^{*}$ & \\
\hline
\end{tabular}

*measles antibody in serum, done in 12 cases, ${ }^{* *}$ EEG-done in 15 cases

were observed in $80 \%$ of the cases. Other EEG changes documented were generalized spikes or slow waves. The classic EEG pattern in SSPE consists of periodic complexes (PC) with generalized, bilaterally symmetrical, high voltage bursts of polyphasic slow waves occurring synchronously throughout the recordings 3,7 , which were also found in the majority of the cases of the present study. Like the present series, both typical and atypical EEG changes in variable proportion were also reported by Ekmekci et al, Praveen kumar et al, and Ozturk et al ${ }^{5,24,25}$.

The most striking features of neuroimaging were cortical atrophy, white matter hyper intense signals in periventricular and parietal region and ischemic change / infract, almost same neuroimaging features has also reported from other studies $4,7,25,26$. The following table compares the clinical presentation and investigation profile of the present study with a similar study from a tertiary care hospital in Dhaka city Alam et $\mathrm{al}^{17}$, documenting the almost similar features in both the studies.

\section{Conclusion:}

SSPE is often not considered because of its rarity and the nonspecific clinical manifestations at onset. Children presenting with deteriorating milestone of development along with myoclonic jerk should raise the suspicion for the diagnosis of SSPE in a developing country like Bangladesh. Investigations like CSF and serum antibody to measles virus and characteristics EEG change may help further in the diagnosis.

\section{References:}

1. Prashanth LK, Taly AB, Ravi V, Sinha S, Rao S. Long term survival in subacute sclerosing panancephalitis: an enigma. Brain Dev. 2006; 28: 447-52.

2. Bojinova VS, Dimova PS, Belopitova LD, Mihailov AS, Gatcheva NL, Mihailov AS et al. Clinical and epidemiological characteristics of subacute sclerosing panencephalitis in Bulgaria during the last 25 years (1978-2002). Eur J Pediatr Neurol. 2004; 8: 89-94.

3. Garg RK. Subacute sclerosing panencephalitis. J Neurol. 2008; 255:1861-71.

4. Kanemura H, Aihara M. Serial diffusion weighted imaging in subacute sclerosing panencephalitis. Pediatr Neurol. 2008; 38:430-4.

5. Ekmekci O, Karasoy H, Gokcay A, Ulku A. Atypical EEG findings in subacute sclerosing panencephalitis. Clin Neurophysiol. 2005; 116: 1762-7.

6. Cruzeiro MM, Vale TC, Pires LA, Franco GM. Atypical Subacute Sclerosing Panencephalitis: case report. Arq NeuroPsiquiatr. 2007; 65 (4a):1030-3. 
7. Garg R K. Subacute sclerosing panencephalitis. Postgrad Med J. 2002; 78: 63-70.

8. Kiyotaro K, Toshiaki T, Akhtar A. Neurological Diseases in Karachi, Pakistan - Elevated Occurrence of Subacute Sclerosing Panencephalitis. Neuroepidemiol. 1988; 7: 66-80.

9. Manayani DJ, Abraham M, Ganamuthu C, Solomon T, Alexander M, Sridharan G. SSPE- The continuing challenge: A study based on serological evidence from a tertiary care centre in India. Indian J Med Microbiol. 2002; 20: 16-8.

10. Mishra B, Kakkar N, Ratho RK, Singhi P, Prabhakar S. Changing trend of SSPE over a period of ten years. Indian J Public Health. 2005; 49: 235-7.

11. Campbell H, Andrews N, Brown KE, Miller E. Review of the effect of measles vaccination on the epidemiology of SSPE. Int J Epidemiol. 2007; 36: $1334-48$.

12. Measles jabs for 33 million Bangladesh children [Online]. 2010 Feb 16 [cited 2010 Mar 21]; Available from: http://www.soschildrensvillages. org.uk/charity-news/archive/2010.

13. Measles situation :A fact sheet. Available from http: / / www.unicef.org/infobycountry/files / MeaslesCampaignFactSheet.pdf

14. Onal AE, Gurses C, Direskeneli GS, Yilmaz G, Demirbilek V, Yentur SP et al. Subacute sclerosing panencephalitis surveillance study in Istambul. Brain Dev. 2006; 28: 183-9.

15. Khadilkar SV, Patil SG, Kulkarni KS. A study of SSPE: Early clinical features. J Pediatr Neurol. 2004; 2: 73-7.

16. Akram M, Naz F, Malik A, Hamid H. Clinical profile of subacute sclerosing panencephalitis. J Coll Physicians Surg Pak. 2008; 18: 485-8.

17. Alam ST, Rahman MM, Akhter S, Rahman SA. Kawser CA. Clinical and laboratory Profile of twenty cases of Subacute Sclerosing
Panencephalitis. Bangladesh J Child Health. 2007; 31: 8-13.

18. Mahadevan A, Vaida SR, Wairagkar NS, Khedekar D, Kovoor JM, Santosh V et al. Case of fulminantSSPE associated with measles genotype D7 from India: an autopsy study. Neuropathol. 2008; 28: 621-6.

19. Norrby E, Kristensson K. Measles virus in the brain. Brain Res Bull. 1997; 44: 213-20.

20. Jin L, Beard S,Hunjan R, Brown DW, Miller E. Characterization of measles virus strain causing SSPE: a study of 11 cases. J Neurovirol. 2002; 8: 335-44.

21. Robertson WC, Clark DB, Markesbery WR. Review of 38 cases of Subacute Sclerosing Panancephalitis: effects of Amantadine on the natural course of the disease. Ann Neurol. 1980; 8: $422-5$.

22. MIcrowell ELISA, Measles IgG \& IgM. Diagnostic Automation Inc. 23961 Craftsman Road, Suite-E/ F, Calabasas, CA, 91302 U.S.A.

23. Gupta E, Dar L, Sing S, Behari M, Broor S. Role of CSF serology in follow-up of subacute sclerosing panencephalitis patient on treatment. Indian $\mathrm{J}$ Med Microbiol. 2006; 24: 131-2.

24. Praveen KS, Sinha S, Taly AB, Jayasree S, Ravi V et al. Electroencephalographic and imaging profile in a subacute sclerosing panencephalitis (SSPE) cohort: a correlative study. Clin Neurophysiol. 2007; 118: 1947-54.

25. Ozturk A, Gurses C, Baykan B, Gokyioit A, Eraksoy M. Subacute Sclerosing Panencephalitis: clinical and magnetic resonance imaging evaluation of 36 patients. J Child Neurol. 2002; 17: 25-9.

26. Oguz KK, Celebi A, Anlar B. MR imaging, diffusionweighted imaging and MR spectroscopy findings in acute rapidly progressive subacute sclerosing panencephalitis. Brain Dev. 2007; 29: 306-11. 